Check for updates

Cite this: RSC Adv., 2018, 8, 42374

\title{
A GSH-responsive nanophotosensitizer for efficient photodynamic therapy $\dagger$
}

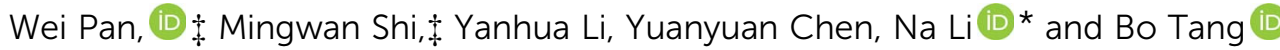

Photodynamic therapy (PDT) is a promising cancer treatment modality, which depends on the reactive oxygen species (ROS) generated by a photosensitizer to kill cancer cells. The lack of selectivity and the over-production of glutathione (GSH) in cancer cells are the two major challenges for efficient and safe cancer PDT because they can cause harm to normal tissues and eliminate ROS in cancer cells. Herein, we report a GSH-responsive nanophotosensitizer based on $\mathrm{CoOOH}$ nanosheets for PDT of cancer. The nanophotosensitizer shows negligible photo-toxicity toward normal cells because of the quenching effect between $\mathrm{CoOOH}$ and photosensitizer Ce6. In the presence of overexpressed GSH, Ce6 molecules can be released into cancer cells because of GSH induced degradation of $\mathrm{CoOOH}$ nanosheets. In vivo experiments demonstrated that the tumor growth was efficiently inhibited by the CoOOH-based PDT strategy. The current nanophotosensitizer represents a promising smart platform to synergistically improve the therapeutic index and safety of PDT.
\end{abstract}

Received 16th October 2018

Accepted 5th December 2018

DOI: $10.1039 / \mathrm{c} 8 \mathrm{ra0} 8549 \mathrm{~h}$

rsc.li/rsc-advances

Cobalt oxyhydroxide $(\mathrm{CoOOH})$ nanosheet, a kind of 2D

\section{Introduction}

Malignant tumors are one of the major chronic diseases that seriously threaten human health. ${ }^{\mathbf{1 , 2}}$ Creating a good strategy to treat cancer cells has attracted increasing attention during the past decades. ${ }^{3}$ Photodynamic therapy (PDT) has been one of the most attractive cancer treatment strategies owing to its excellent controllability, short treatment cycle and low dark toxicity. ${ }^{\mathbf{4 - 1 0}}$ The major mechanism of PDT is suggested to be the generation of reactive oxygen species (ROS), due to the energy transfer between the excited photosensitizer and the nearby oxygen molecules, which can further denaturalize the biomolecules in cancer cells. ${ }^{11-20}$ However, it is reported that the generated ROS can be removed by superoxide dismutase (SOD) and catalase (CAT), etc. ${ }^{21}$ Moreover, the overexpressed glutathione (GSH) in cancer cells can directly react with ROS and further prevent them from oxidation stress. ${ }^{22,23}$ Notably, the generated ROS is even more toxic to normal cells due to the lower GSH concentration and higher oxygen content, which resulted in the side effects of PDT. ${ }^{24-26}$ Therefore, it is highly desired to develop a safe and efficient PDT platform for PDT with enhanced selectivity and reduced side effects.

College of Chemistry, Chemical Engineering and Materials Science, Key Laboratory of Molecular and Nano Probes, Ministry of Education, Collaborative Innovation Center of Functionalized Probes for Chemical Imaging in Universities of Shandong, Institute of Molecular and Nano Science, Shandong Normal University, Jinan 250014, P. R. China. E-mail: lina@sdnu.edu.cn; Fax: +86-531-86180017

$\dagger$ Electronic supplementary information (ESI) available. See DOI: 10.1039/c8ra08549h

\$ These authors contributed equally to this paper. nanomaterial, has been widely used in the biological fields because of its easy preparation, functionalization and high biocompatibility. ${ }^{27,28}$ Moreover, CoOOH nanosheets have a large specific surface area, which makes it suitable for drug loading and substrate detection. ${ }^{29,30}$ Most importantly, the optical quenching properties of $\mathrm{CoOOH}$ makes it an ideal platform for photosensitizer delivery and responsive cancer treatment, which can significantly reduce the toxicity of photosensitizer before reaching target sites. After $\mathrm{CoOOH}$ reacted with cancer cell-overexpressed antioxidant $\mathrm{GSH}$, the $\mathrm{CoOOH}$ will be collapsed and the quenched photosensitizer can be reactivated, which is helpful to synergistically enhance the safety and efficiency of PDT due to the selective activation and GSH elimination.

On this basis, we designed and synthesized a CoOOH-based nanophotosensitizer as a smart PDT platform for cancer PDT. The nanophotosensitizer was synthesized by directly decorating photosensitizer chlorin e6 (Ce6) onto $\mathrm{CoOOH}$ nanosheets through an amide linkage between the amino group and the carboxyl group (as shown in Scheme 1). In this nanophotosensitizer, $\mathrm{CoOOH}$ plays two important roles, one is the carrier with quenching capacity, which can deliver Ce6 molecules into cancer cells while prevent the generation of ${ }^{1} \mathrm{O}_{2}$ in normal cells. The other is as an oxidant that can reduce the intracellular GSH. When the nanophotosensitizer was injected into the tumor site, the reaction of $\mathrm{CoOOH}$ nanosheets with intratumoral GSH resulted in the degradation of $\mathrm{CoOOH}$ and the release of Ce6. And then, the reduction of intracellular GSH concentration resulted lower resistance of cancer cells toward ${ }^{1} \mathrm{O}_{2}$, so the tumor cells can be effectively killed under the laser 


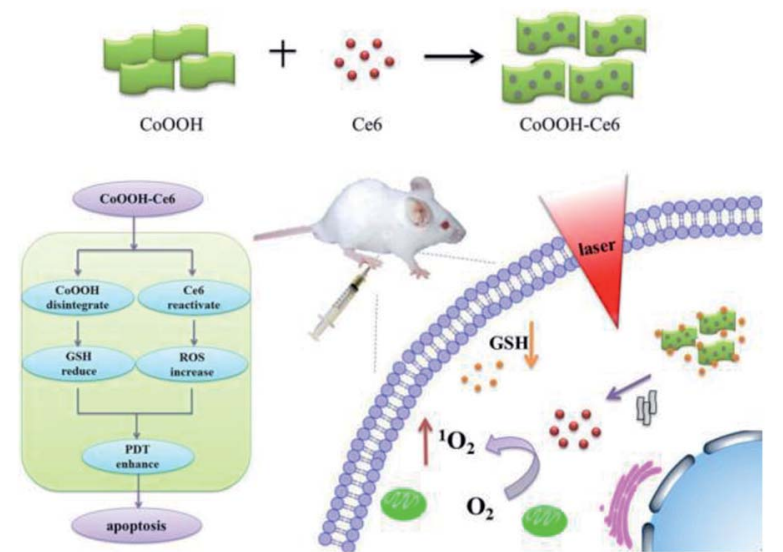

Scheme 1 Schematic illustration of the synthesis of the $\mathrm{CoOOH}-\mathrm{Ce} 6$ and photodynamic therapy in the cell with nanophotosensitizer.

irradiation. Therefore, we believe that the current nanophotosensitizer should be a promising candidate for smart cancer therapy with enhanced efficiency and selectivity.

\section{Experimental}

\section{Materials and instruments}

Cobalt chloride hexahydrate $\left(\mathrm{CoCl}_{2} \cdot 6 \mathrm{H}_{2} \mathrm{O}\right)$ was purchased from Tianjin Guangfu (Tianjin, China). N,N-Dimethylformamide (DMF), sodium hypochlorite ( $\mathrm{NaClO}$ ), sodium hydroxide $(\mathrm{NaOH})$ were purchased from China National Pharmaceutical (Shanghai, China). 3-(4,5-Dimethylthiazol-2-yl)-2,5diphenyltetrazolium bromide (MTT) and GSH were purchased from Sigma Aldrich (U.S.). 3-Aminopropyltriethoxysilane (APTES) was purchased from Alfa Aesar (Tianjin, China). 1Ethyl-3-(3-dimethylaminopropyl)carbodiimide (EDC), and $\mathrm{N}$ hydroxysuccinimide (NHS) were obtained from Alfa Aesar (Tianjin, China). Disodium of 9,10-anthracenediylbis(methylene)dimalonic acid (ABMD) was purchased from Sigma Chemical Company. 2', $7^{\prime}$-Dichlorofluorescein-diacetate (DCFH-DA), was purchased from Sigma-Aldrich (St. Louis, MO, USA). The mouse breast cancer cell line (4T1 cells) and the mouse normal lung epithelial cell line (TC-1 cells) were purchased from Shanghai AOLU Biological Technology Co., Ltd. Female Balb/c mice (4-6 weeks, 18-20 g) were purchased from Shandong University Laboratory Animal Center. All the chemicals were used without further purification. Ultrapure water $(18.2 \mathrm{M} \Omega \mathrm{cm})$ was used throughout the experiments.

Transmission electron microscopy (TEM) was carried out on a HT7700 electron microscope (Hitachi, Japan). UV-Vis absorption spectra were measured on a pharmaspec UV1700 UV-Vis spectrophotometer (Shimadzu, Japan). Fluorescence spectra were obtained with FLS-980 Edinburgh fluorescence spectrometer with a xenon lamp. The absorbance of formazan was measured with a microplate reader (Synergy 2, Biotek, USA) in the MTT assay. Confocal fluorescence imaging studies were performed with a TCS SP5 confocal laser scanning microscopy (Leica, Germany).

\section{Synthesis of amino-functionalized cobalt oxyhydroxide nanoflakes (CoOOH-NH $\left.{ }_{2}\right)$}

$\mathrm{CoOOH}$ was synthesized following previous method. Typically, $30 \mathrm{~mL}$ of $\mathrm{NaOH}(0.8 \mathrm{M})$ and $30 \mathrm{~mL}$ of $\mathrm{NaClO}(0.1 \mathrm{M})$ were added to a $30 \mathrm{~mL}$ of $\mathrm{CoCl}_{2}(10 \mathrm{mM})$ solution, followed by $10 \mathrm{~min}$ sonication. The precipitate was then washed with water for three times and dried in oven. The as synthesized neutralized CoOOH nanosheets $(10 \mathrm{mg})$ were dissolved into $5 \mathrm{~mL}$ anhydrous DMF, and $40 \mu \mathrm{L}$ APTES was added to the mixture for $12 \mathrm{~h}$ at $80{ }^{\circ} \mathrm{C}$ under continuous mechanical stirring to activate the amino group. The product was washed twice with ethanol and water, respectively, and finally dispersed in $2 \mathrm{~mL}$ water to store at room temperature. The amino groups were measured by ninhydrin: $1 \%$ of ninhydrin was added to $1 \mathrm{~mL} \mathrm{CoOOH}-\mathrm{NH}_{2}$ or supernatant of $\mathrm{CoOOH}-\mathrm{NH}_{2}$, and then brought to boiling for $30 \mathrm{~min}$.

\section{Preparation of $\mathrm{CoOOH}-\mathrm{Ce} 6$ nanophotosensitizer}

EDC $(20 \mu \mathrm{mol})$ and NHS $(20 \mu \mathrm{mol})$ were mixed with Ce6 $(2 \mu \mathrm{mol})$ in buffer in the dark for $30 \mathrm{~min}$. Afterwards, $400 \mu \mathrm{L}$ of the previously prepared $\mathrm{CoOOH}-\mathrm{NH}_{2}$ solution was added dropwise to the solution, the reaction was stirred in the dark for $24 \mathrm{~h}$. After washing three times with ethanol, the supernatant was collected, and the precipitate was washed with water for three times. The precipitate was finally dispersed in $2 \mathrm{~mL}$ of water.

\section{Quantification of the Ce6 on the nanophotosensitizer}

Ethanol solutions of different concentrations Ce6 $(50 \mathrm{mM}$, $100 \mathrm{mM}, 150 \mathrm{mM}, 200 \mathrm{mM}, 250 \mathrm{mM}, 300 \mathrm{mM}, 350 \mathrm{mM}$, $400 \mathrm{mM}, 450 \mathrm{mM}, 500 \mathrm{mM}$ ) were prepared, and the fluorescence intensity (excitation wavelength: $405 \mathrm{~nm}$, emission wavelength: $660 \mathrm{~nm}$ ) was measured. The standard curve was made by the fluorescence data.

\section{Ce6 release test}

Different concentration of GSH $(0.5 \mathrm{mM}, 1 \mathrm{mM}, 2 \mathrm{mM}, 4 \mathrm{mM}$, $6 \mathrm{mM}, 8 \mathrm{mM})$ were added to the solution of $\mathrm{CoOOH}-\mathrm{Ce} 6(20 \mu \mathrm{L}$, $1 \mathrm{mg} \mathrm{mL}{ }^{-1}$ ) respectively, and then stirred for $24 \mathrm{~h}$ at room temperature. The fluorescence intensity was measured as the same procedure above. The $\mathrm{CoOOH}-\mathrm{Ce} 6$ of supernatant was measured the fluorescence intensity.

\section{The ${ }^{1} \mathrm{O}_{2}$ detection experiment}

ABMD was selected as an indicator for the detection of singlet oxygen. ABMD reacts with singlet oxygen to decrease absorbance of ABMD. Three replicates of the same concentration of photosensitizer Ce 6 were taken and ABMD was added to each of the three solutions. The $655 \mathrm{~nm}$ wavelength laser was irradiated for $0 \mathrm{~min}, 15 \mathrm{~min}$ and $30 \mathrm{~min}$, and the change in ABMD absorbance was observed and determined. Then three replicates of the same concentration of nanophotosensitizer were taken. $0,10 \mu \mathrm{L}$ and $20 \mu \mathrm{L}$ of different amounts of $5 \mathrm{mM} \mathrm{GSH}$ were added, respectively, and ABMD was added to the three solutions. The laser of $655 \mathrm{~nm}$ wavelength was irradiated for 30 min. The change in UV absorption of ABMD was measured. 


\section{Confocal fluorescence imaging}

The $4 \mathrm{~T} 1$ cells and TC- 1 cells were cultured in RPMI-1640 culture medium containing $1 \%$ of double antibodies and $10 \%$ of serum at $37{ }^{\circ} \mathrm{C}$ in $5 \% \mathrm{CO}_{2}$ atmosphere. They were inoculated into confocal dishes after a period of incubation. The cells were incubated for $12 \mathrm{~h}$ until they were adherent, and then RPMI1640 medium was discarded, and CoOOH-Ce6 $(40 \mu \mathrm{L}, 1 \mathrm{mg}$ $\mathrm{mL}^{-1}$ ) nanophotosensitizer was added thereto. The cultivation was continued for $8 \mathrm{~h}$. Then RPMI-1640 medium with the nanophotosensitizer was discarded and excess nanophotosensitizer that did not enter the cells was washed away with PBS. The cells were examined with CLSM with $405 \mathrm{~nm}$ excitation.

\section{Cell MTT assay}

$4 \mathrm{~T} 1$ cells were seeded in a 96-well plate and further cultured for $24 \mathrm{~h}$. After removing the culture medium, cells were incubated with different concentrations of $\mathrm{CoOOH}-\mathrm{Ce} 6(20,40,80 \mu \mathrm{g}$ $\mathrm{mL}^{-1}$ ) nanosystem at $37^{\circ} \mathrm{C}$ for $6 \mathrm{~h}$. Afterwards, the cells were replaced with $200 \mu \mathrm{L}$ of fresh medium and further cultured for $48 \mathrm{~h}$. The cells without any treatment as the control group were incubated for $48 \mathrm{~h}$ at $37{ }^{\circ} \mathrm{C}$. In addition, $200 \mu \mathrm{L}$ MTT solutions $\left(0.5 \mathrm{mg} \mathrm{mL} \mathrm{m}^{-1}\right.$ in PBS) were added to each well and incubated for $4 \mathrm{~h}$. The formazan crystals formed by viable cells were solubilized in $200 \mu \mathrm{L}$ dimethylsulfoxide and then the absorbance value was measured at $490 \mathrm{~nm}$ with microplate reader. To evaluate different intensity of laser for 4T1 cells, MTT assays in $4 \mathrm{~T} 1$ cells with each sample were performed for $6 \mathrm{~h}$ at $37{ }^{\circ} \mathrm{C}$, respectively. The cells were replaced under the $655 \mathrm{~nm}$ laser with different intensity $\left(25,50 \mathrm{~mW} \mathrm{~cm}^{-2}\right)$. After $48 \mathrm{~h}$ incubation, MTT assays were carried out as the same procedure described above.

\section{Animal studies}

All animal experiments were carried out and following the Principles of Laboratory Animal Care (People's Republic of China). Specific pathogen-free (SPF) female Balb/c mice were used in accordance with the guidelines of the principles of the Animal Investigation Committee approved by Biology Institute of Shandong Academy of Science, China. Murine tumor xenograft models were generated by the subcutaneous injection of 1 $\times 10^{6} 4 \mathrm{~T} 1$ cells in PBS $(150 \mu \mathrm{L})$ into the flank of female mice (4-6 weeks old, $\sim 20 \mathrm{~g})$. When the tumor volume reached $30-50 \mathrm{~mm}^{3}$, the mice ( $n \geq 4$ per group) were injected with $\mathrm{CoOOH}-\mathrm{Ce} 6(2 \mathrm{mg}$ $\left.\mathrm{mL}^{-1}, 50 \mu \mathrm{L}\right)$ (group 1), CoOOH-Ce6 $\left(2 \mathrm{mg} \mathrm{mL}{ }^{-1}, 50 \mu \mathrm{L}\right)$ (group 2), Ce6 $(0.8 \mu \mathrm{M}, 50 \mu \mathrm{L})$ (group 3), PBS (50 $\mu \mathrm{L})$ (group 4), and nothing (group 5) for the first day, and the group 1, 3, 5 were

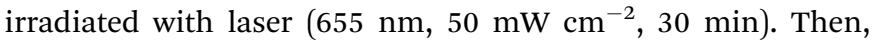
these materials were intratumorally injected into the mouse tumor. In addition, these materials were injected at day 1, 3 and 5 for three times. Tumor volumes and body weights in each group were monitored for 14 days. By recording the tumor size of the mice within 14 days, the efficacy of the treatment in the control and experimental groups were evaluated. The tumor volume $(V)$ was determined by measuring length $(L)$ and width
$(W)$, and calculated as $V=L \times W^{2} / 2$. The relative tumor volumes were calculated for each mouse as $V / V_{0}\left(V_{0}\right.$ was the tumor volume when the treatment was initiated).

\section{Results and discussion}

\section{Synthesis and characterization of the nanophotosensitizer}

The $\mathrm{CoOOH}$ nanosheets were synthesized using a previously reported cobalt chloride oxidation method. ${ }^{27}$ APTES was employed to functionalize $\mathrm{CoOOH}$ nanosheets, and the final nanophotosensitizer was prepared by decorating Ce6 onto the aminated $\mathrm{CoOOH}$ through an amino bond. According to the transmission electron microscope (TEM) images (Fig. 1A and B), the $\mathrm{CoOOH}$ nanosheets displayed an average size of approximately $80 \mathrm{~nm}$ and the structure of $\mathrm{CoOOH}$ did not change obviously after the two-step modification. From the ninhydrin experiment as shown in Fig. 1C, it was clear that the precipitate turned blue-purple while no color change can be observed from the supernatant, indicating that the $\mathrm{CoOOH}$ has been successfully aminated and no amino group was present in the supernatant. Zeta potential of these materials was also tested (Fig. 1D). The potential of the CoOOH nanosheets was approximately $-5.7 \pm 0.4 \mathrm{mV}$ after surface amination, and the potential became $+4.6 \pm 0.4 \mathrm{mV}$ due to the successful modification of the positively charged group. After the photosensitizer Ce6 was attached, the potential reduced to $-2.8 \pm 0.5 \mathrm{mV}$, demonstrated the successful synthesis of $\mathrm{CoOOH}-\mathrm{Ce} 6$ nanophotosensitizer. The amount of Ce6 molecules attached to $\mathrm{CoOOH}$ was quantified through a drawn standard curve. After measuring the fluorescence intensity of the supernatant, the Ce6 content of the final nanophotosensitizer was calculated to be $410 \mathrm{nmol} \mathrm{mg}^{-1}$ (Fig. S1 and S2 $\dagger$ ). To test the GSH responsive
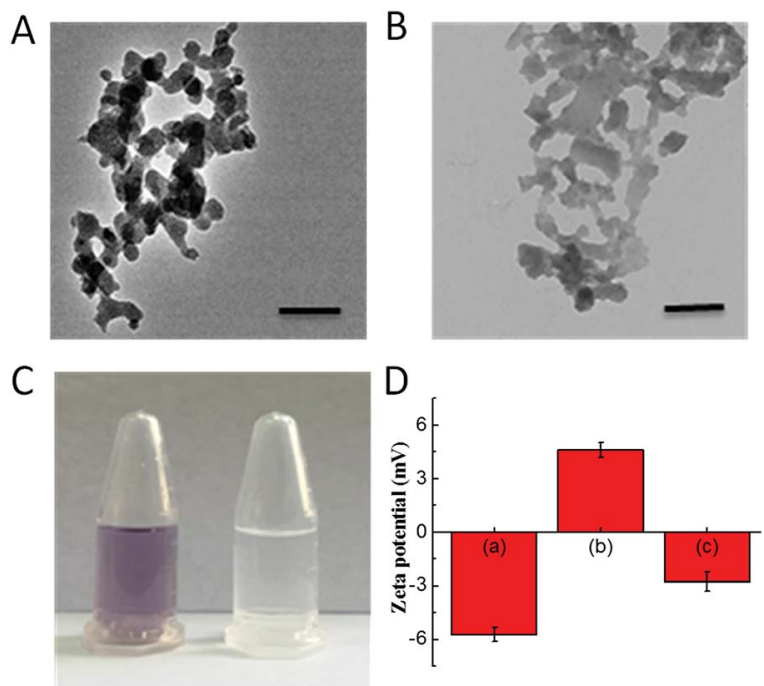

Fig. 1 Characterization of the nanomaterials. TEM of $\mathrm{COOOH}(\mathrm{A})$ and nanophotosensitizer (B). Scale bars are $200 \mathrm{~nm}$. (C) The verification of amination of $\mathrm{CoOOH}-\mathrm{NH}_{2}$ with ninhydrin experiment. On the left is $\mathrm{CoOOH}-\mathrm{NH}_{2}$, and on the right is supernatant. (D) Zeta potential of each step of the modification: (a) $\mathrm{CoOOH}$; (b) $\mathrm{CoOOH}-\mathrm{NH}_{2}$; (c) nanophotosensitizer. 
degradation of $\mathrm{COOOH}$, we performed the TEM imaging and observed the morphology change of the GSH-degraded $\mathrm{CoOOH}$ nanosheets. As shown in Fig. S5, $\dagger$ the $\mathrm{CoOOH}$ nanosheets were degraded after incubated in GSH solution. Moreover, color changes of the $\mathrm{CoOOH}$ nanosheets after incubated in GSH solution were recorded at different times. Fig. S6 $\uparrow$ indicated that the $\mathrm{CoOOH}$ nanosheets gradually degraded after incubation with GSH.

\section{Fluorescence recovery of $\mathrm{Ce} 6$ in the nanophotosensitizer}

Because the photosensitizer Ce6 was covalently attached onto the $\mathrm{CoOOH}$, the quenching effect resulted an 'OFF' state and the nanophotosensitizer cannot generate ${ }^{1} \mathrm{O}_{2}$ under irradiation.

After reacted with $\mathrm{GSH}$, the $\mathrm{CoOOH}$ nanosheets can be reduced into $\mathrm{Co}^{2+}$, and Ce6 can thus be reactivated and used for cancer cell selective PDT. To demonstrate the reaction between GSH and $\mathrm{CoOOH}$ as well as the GSH triggered fluorescence recovery, the fluorescent spectra of $\mathrm{Ce} 6$ were recorded after $\mathrm{CoOOH}-\mathrm{Ce} 6$ reacted with different amounts of GSH. As shown in Fig. 2A, the fluorescence intensity of the solution increased linearly with the increase of GSH content, which was attributed to the degradation of $\mathrm{CoOOH}$. It suggested that the current nanophotosensitizer could be re-activated by GSH.

\section{Detection of the reactive oxygen species production}

ABMD (disodium salt) was used as an indicator for detecting ${ }^{1} \mathrm{O}_{2}$. Since ABMD can react with ${ }^{1} \mathrm{O}_{2}$ to produce endoperoxide, which will cause the absorbance intensity decrement of ABMD. ${ }^{31} \mathrm{Ce} 6$ was irradiated with laser at different times, and it was verified that the photosensitizer $\mathrm{Ce} 6$ can produce more ${ }^{1} \mathrm{O}_{2}$ with the extension of the irradiation time (Fig. S3 $†$ ). Therefore, the ${ }^{1} \mathrm{O}_{2}$ produced by $\mathrm{CoOOH}-\mathrm{Ce} 6$ under different $\mathrm{GSH}$ was investigated. As shown in the Fig. $2 \mathrm{~B}$, with the amount of GSH increased from $0 \mu \mathrm{L}$ to $10 \mu \mathrm{L}$ to $20 \mu \mathrm{L}$, the UV-Vis absorption of ABMD obviously decreased under laser irradiation, indicating that GSH degraded $\mathrm{CoOOH}$ nanosheets, and reactivation of $\mathrm{Ce} 6$ effectively produced ${ }^{1} \mathrm{O}_{2}$. Intracellular ROS production was detected with DCFH-DA ${ }^{32}$ to demonstrate the nanophotosensitizer can be used for cancer cell selective PDT. As shown in Fig. S7, $\uparrow$ the strong green fluorescence indicated that ROS can be produced when irradiated with NIR laser. These
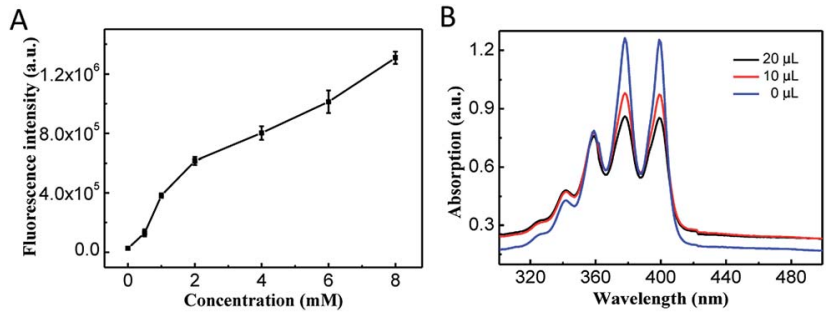

Fig. 2 (A) Fluorescence intensity of $\mathrm{Ce} 6$ after $\mathrm{CoOOH}-\mathrm{Ce} 6$ reacted with different concentrations of GSH. (B) The absorbance values of ABMD were measured after different amounts of GSH were added and irradiated with $655 \mathrm{~nm}$ laser. results demonstrated that the nanophotosensitizer could be used for GSH responsive PDT.

\section{Therapeutic effect of the nanophotosensitizer in living cells}

For confirming the optimum laser parameters and further investigating the PDT effect of the nanophotosensitizer in living cells, MTT experiments were carried out. ${ }^{33} 4 \mathrm{~T} 1$ cells were treated with different intensities $\left(25,50 \mathrm{~mW} \mathrm{~cm}{ }^{-2}\right)$ of laser irradiation alone and different amounts of $\mathrm{CoOOH}-\mathrm{Ce} 6(20,40,80 \mu \mathrm{g}$ $\mathrm{mL}^{-1}$ ). As shown in Fig. 3A, cells showed negligible cell viability decrement under laser irradiated alone, which means $655 \mathrm{~nm}$ laser irradiation cause little harm to cells even after $30 \mathrm{~min}$. With the increase of the nanophotosensitizer concentration from 20,40 , to $80 \mu \mathrm{g} \mathrm{mL}^{-1}$, the cell viability decreased from $96 \%$

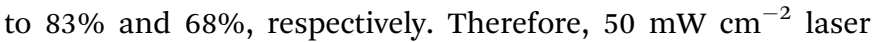
intensity and $40 \mu \mathrm{g} \mathrm{mL}{ }^{-1} \mathrm{CoOOH}-\mathrm{Ce} 6$ were chosen for the following experiments. To demonstrate the effect on the survival rate of cancer cells for the NIR irradiated $\mathrm{CoOOH}$, different concentrations of $\mathrm{CoOOH}$ nanosheets were added to $4 \mathrm{~T} 1$ cells and incubated for $6 \mathrm{~h}$. After illuminated with a $655 \mathrm{~nm}$ laser for 30 minutes, the cells were further incubated for another $48 \mathrm{~h}$ and the survival rate of the treated cells was determined. Fig. S4 $\dagger$ showed that no obvious suppressing effect was observed for the selected concentration $\left(40 \mu \mathrm{g} \mathrm{mL}{ }^{-1}\right)$. Next, MTT assay was further carried out to test the therapeutic effect of the nanophotosensitizer. Fig. 3B showed that the cell survival rate was high, when incubated with $\mathrm{Ce} 6, \mathrm{CoOOH}-\mathrm{Ce} 6$ or laser irradiation alone. While the cell viability of the NIR irradiated $\mathrm{CoOOH}-\mathrm{Ce} 6$ group decreased sharply to $8.3 \%$, indicating that the nanophotosensitizer can significantly enhance the therapeutic effect of cancer PDT owing to the GSH clearance capability and ${ }^{1} \mathrm{O}_{2}$ generation. These results confirmed that the nanophotosensitizer was a promising platform for highly efficient PDT.

To determine the selectivity of the nanophotosensitizer for cancer cells, nanophotosensitizer $\left(40 \mu \mathrm{g} \mathrm{mL}^{-1}\right)$ was employed to incubate with $4 \mathrm{~T} 1$ cells and TC- 1 cells. The fluorescence intensity of Ce6 was evaluated by CLSM after $8 \mathrm{~h}$ incubation. As shown in Fig. 4, the fluorescence intensity of Ce6 was brighter in cancer cells than in normal cells. This is because the GSH levels
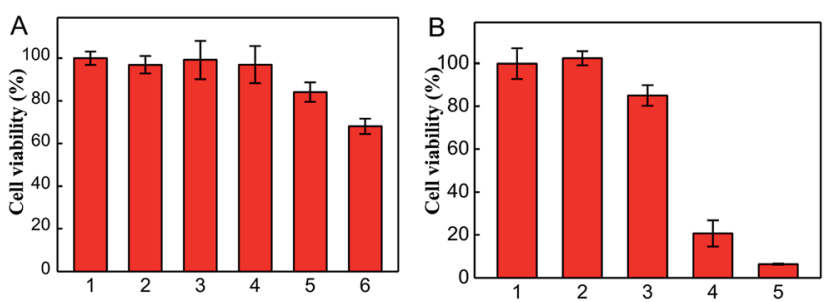

Fig. 3 (A) The cell viabilities of $4 \mathrm{~T} 1$ cells after different treatments: without any treatment (1), irradiated with $655 \mathrm{~nm}$ laser at the intensity of 25 (2) and 50 (3) $\mathrm{mW} \mathrm{cm}^{-2}$ for $30 \mathrm{~min}$, respectively; incubated with the $\mathrm{CoOOH}-\mathrm{Ce} 6\left(20 \mu \mathrm{g} \mathrm{mL}^{-1}\right.$ (4); $40 \mu \mathrm{g} \mathrm{mL}^{-1}$ (5); $\left.80 \mu \mathrm{g} \mathrm{mL}^{-1}(6)\right)$ without laser irradiation. (B) Cell viabilities of $4 \mathrm{~T} 1$ cells after different treatments: blank control (1), $\mathrm{Ce} 6\left(38 \mu \mathrm{g} \mathrm{mL}^{-1}\right)$ only (2), $\mathrm{CoOOH}-\mathrm{Ce} 6$ (40 $\mu \mathrm{g} \mathrm{mL}^{-1}$ ) only (3), $\mathrm{Ce} 6+$ laser (4), $\mathrm{CoOOH}-\mathrm{Ce} 6+$ laser (5), the intensity was $50 \mathrm{~mW} \mathrm{~cm}^{-2}$. 

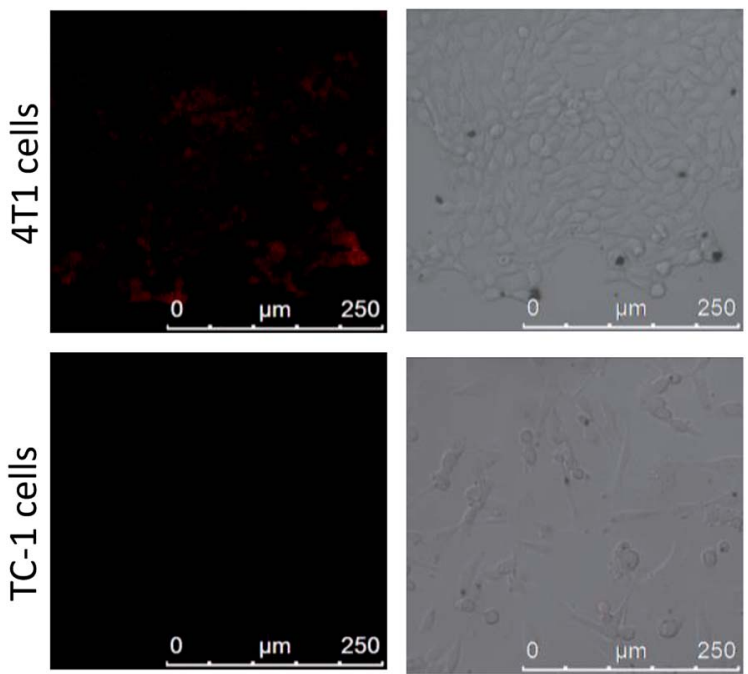

Fig. 4 Confocal imaging of $4 \mathrm{~T} 1$ cells and TC-1 cells after incubated with $\mathrm{CoOOH}-\mathrm{Ce} 6$ nanophotosensitizer $\left(40 \mu \mathrm{g} \mathrm{mL}^{-1}\right)$ for $8 \mathrm{~h}$.

in tumor cells are overexpressed, thus more $\mathrm{CoOOH}$ can be degraded, resulted in higher fluorescence recover rate and stronger fluorescence intensity, which is critical for cancer PDT with high selectivity.

\section{Evaluation of the nanophotosensitizer for PDT in vivo}

Before evaluating the PDT effect in vivo, the haemolytic effect was determined (Fig. S8†). The results suggested that the nanophotosensitizer had non-hemolytic effect toward the red blood cells of mice, indicating that $\mathrm{CoOOH}-\mathrm{Ce} 6$ can be used for in vivo PDT. 4T1 tumor-bearing mouse models were used to demonstrate that the synthetic nanophotosensitizer have the capacity for treating tumors in vivo. The $4 \mathrm{~T} 1$ cells were first injected into the armpit of the mice. The tumor-bearing mice were divided into five groups for different treatments: control (PBS only), laser irradiation only, Ce6 with laser irradiation, $\mathrm{CoOOH}-\mathrm{Ce} 6$ only and $\mathrm{CoOOH}-\mathrm{Ce} 6$ with laser irradiation. After 5 days, the nanophotosensitizer $\mathrm{CoOOH}-\mathrm{Ce} 6$ were dispersed into the PBS buffer solution $\left(2 \mathrm{mg} \mathrm{mL}^{-1}, 50 \mu \mathrm{L}\right)$ and intratumorally injected into the mouse tumor at day 1, 3 and 5 for three times. The $655 \mathrm{~nm}$ laser with a power density of $50 \mathrm{~mW}$ $\mathrm{cm}^{-2}$ was used to irradiate the tumor area for $30 \mathrm{~min}$ each time. By recording tumor volumes and body weights of the mice
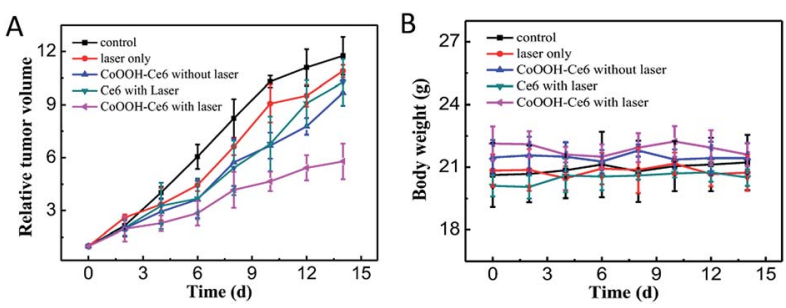

Fig. 5 Tumor growth curves (A) and mouse body weight curves (B) of different treatments of tumor-bearing mice: PBS only, laser only, $\mathrm{CoOOH}-\mathrm{Ce} 6$ without laser, $\mathrm{Ce} 6$ with laser, $\mathrm{CoOOH}-\mathrm{Ce} 6$ with laser. within 14 days, the efficacy of the treatment in the control and experimental groups were evaluated. The experimental results from Fig. 5A indicated that the treatments with only laser irradiation and with the nanophotosensitizer alone had no tumor inhibition capability. Treatment with Ce6 alone could inhibit tumor growth under laser irradiation, which showed that the photosensitizer Ce6 can generate ${ }^{1} \mathrm{O}_{2}$ to kill tumor cells under illumination. However the efficiency remains poor, and the resistance was mostly date from the over-expressed GSH. Compared with the control group, the nanophotosensitizer we designed exhibited more pronounced inhibitory effects on tumors under light irradiation. These results suggested that the nanophotosensitizer had better tumor therapeutic effect, demonstrating that $\mathrm{CoOOH}$ is a promising platform to enhance the PDT efficiency due to the GSH elimination. As shown in Fig. 5B, there was no significant change in the body weight of the mice during treatment, further indicating that the nanophotosensitizer was non-toxic. Afterwards, H\&E staining assays on each group of mice. No obvious lesions can be observed in all tissues and organs (heart, liver, spleen, lung and kidney) (Fig. S9†). This further demonstrated that $\mathrm{CoOOH}-\mathrm{Ce} 6$ nanophotosensitizer had good biocompatibility and was promising for cancer PDT.

\section{Conclusions}

In summary, we designed and synthesized a CoOOH-based smart nanophotosensitizer for PDT of cancer. The nanophotosensitizer was synthesized by directly decorating photosensitizer Ce6 onto aminated $\mathrm{CoOOH}$ nanosheets via amide bonds. This nanophotosensitizer was quenched in normal cells and it showed little damage to normal cells. When entering cancer cells, $\mathrm{CoOOH}$ nanosheets can be degraded by the overexpressed GSH in cancer cells, resulting in the release of Ce6 molecules and the effectively production of ${ }^{1} \mathrm{O}_{2}$ under laser excitation. At the same time, the consumption of GSH reduced the tolerance of cancer cells to ${ }^{1} \mathrm{O}_{2}$. Therefore, this nanophotosensitizer exhibited good selectivity and enhanced cancer treatment effects, which were confirmed both in vitro and in vivo. We anticipate that the nanophotosensitizer can provide new insights for cancer PDT.

\section{Conflicts of interest}

There are no conflicts or competing financial interest.

\section{Acknowledgements}

This work was supported by the National Natural Science Foundation of China (21874086, 21775094, 21505087).

\section{Notes and references}

1 L. A. Torre, F. Bray, R. L. Siegel, J. Ferlay, J. Lortet-Tieulent and A. Jemal, Ca-Cancer J. Clin., 2015, 65, 87-108.

2 G. Delaney, S. Jacob, C. Featherstone and M. Barton, Cancer, 2005, 104, 1129-1137. 
3 D. Peer, J. M. Karp, S. Hong, O. C. Farokhzad, R. Margalit and R. Langer, Nat. Nanotechnol., 2007, 2, 751-760.

4 E. J. Dennis, G. J. Dolmans, D. Fukumura and R. K. Jain, Nat. Rev. Cancer, 2003, 3, 380-387.

5 A. P. Castano, P. Mroz and M. R. Hamblin, Nat. Rev. Cancer, 2006, 6, 535-545.

6 C. M. Moore, D. Pendse, M. Emberton, D. Pendse and M. Emberton, Nat. Clin. Pract. Urol., 2009, 6, 18-30.

7 J. F. Lovell, W. Tracy, B. Liu, J. Chen and G. Zheng, Chem. Rev., 2010, 110, 2839-2857.

8 Z. Hou, Y. Zhang, K. Deng, Y. Chen, X. Li, X. Deng, Z. Cheng, H. Lian, C. Li and J. Lin, ACS Nano, 2015, 9, 2584-2599.

9 S. S. Lucky, K. C. Soo and Y. Zhang, Chem. Rev., 2015, 115, 1990-2042.

10 Z. Yu, Y. Ge, Q. Sun, W. Pan, X. Wan, N. Li and B. Tang, Chem. Sci., 2018, 9, 3563-3569.

11 M. Niedre, M. S. Patterson and B. C. Wilson, Photochem. Photobiol., 2002, 75, 382-391.

12 K. M. Kuimova, S. W. Botchway, A. W. Parker, M. Balaz, H. A. Collins, H. L. Anderson, K. Suhling and P. R. Ogilby, Nat. Chem., 2009, 1, 69-73.

13 M. Ethirajan, Y. Chen, P. Joshi and R. K. Pandey, Chem. Soc. Rev., 2011, 40, 340-362.

14 H. Yuan, H. Chong, B. Wang, C. Zhu, L. Liu, Q. Yang, F. Lv and S. Wang, J. Am. Chem. Soc., 2012, 134, 13184-13187.

15 R. Liang, R. Tian, L. Ma, L. Zhang, Y. Hu, J. Wang, M. Wei, D. Yan, D. G. Evans and X. Duan, Adv. Funct. Mater., 2014, 24, 3144-3151.

16 Z. Yu, Q. Sun, W. Pan, N. Li and B. Tang, ACS Nano, 2015, 9, 11064-11074.

17 Z. Yu, W. Pan, N. Li and B. Tang, Chem. Sci., 2016, 7, 42374244.

18 J. Xu, W. Han, Z. Cheng, P. Yang, H. Bi, D. Yang, N. Niu, F. He, S. Gaia and J. Lin, Chem. Sci., 2018, 9, 3233-3247.
19 J. Xu, W. Han, P. Yang, T. Jia, S. Dong, H. Bi, A. Gulzar, D. Yang, S. Gai, F. He, J. Lin and C. Li, Adv. Funct. Mater., 2018, 28, 1803804.

20 L. Feng, S. Gai, Y. Dai, F. He, C. Sun, P. Yang, R. Lv, N. Niu, G. An and J. Lin, Chem. Mater., 2018, 30, 526-539.

21 Z. Meng, Inhalation Toxicol., 2003, 15, 181-195.

22 L. Cheng, C. Wang, L. Feng, K. Yang and Z. Liu, Chem. Rev., 2014, 114, 10869-10939.

23 C. Liang, L. Xu, G. Song and Z. Liu, Chem. Soc. Rev., 2016, 45, 6250-6269.

24 H. Fan, G. Yan, Z. Zhao, X. Hu, W. Zhang, H. Liu, X. Fu, T. Fu, X.-B. Zhang and W. Tan, Angew. Chem., Int. Ed., 2016, 128, 5567-5572.

25 E. Ju, K. Dong, Z. Chen, Z. Liu, C. Liu, Y. Huang, Z. Wang, F. Pu, J. Ren and X. Qu, Angew. Chem., 2016, 128, 1163911643.

26 S. L. Cramer, A. Saha, J. Liu, S. Tadi, S. Tiziani, W. Yan, K. Triplett, C. Lamb, S. E. Alters, S. Rowlinson, Y. J. Zhang, M. J. Keating, P. Huang, J. DiGiovanni, G. Georgiou and E. Stone, Nat. Med., 2017, 23, 120-127.

27 N. Li, Y. Li, Y. Han, W. Pan, T. Zhang and B. Tang, Anal. Chem., 2014, 86, 3924-3930.

28 L. Li, C. Wang, K. Liu, Y. Wang, K. Liu and Y. Lin, Anal. Chem., 2015, 87, 3404-3411.

29 Y. Cen, J. Tang, X.-J. Kong, S. Wu, J. Yuan, R.-Q. Yu and X. Chu, Nanoscale, 2015, 7, 13951-13957.

30 Y.-M. Wang, J.-W. Liu, J.-H. Jiang and W. Zhong, Anal. Bioanal. Chem., 2017, 409, 4225-4232.

31 N. Li, H. Yang, Z. Yu, Y. Li, W. Pan, H. Wang and B. Tang, Chem. Sci., 2017, 8, 2816-2822.

32 L. Huang, Z. Li, Y. Zhao, J. Yang, Y. Yang, A. Pendharkar, Y. Zhang, S. Kelmar, L. Chen, W. Wu, J. Zhao and G. Han, Adv. Mater., 2017, 29, 1604789.

33 N. Li, C. Chang, W. Pan and B. Tang, Angew. Chem., Int. Ed., 2012, 51, 7426-7430. 